Rike Bolte

\title{
'Los rubios' destiñen a mnemosina Playing Memory en el nuevo cine argentino. Entre arqueología, stop-(e)motion y vudu sintético ${ }^{1}$
}

\author{
Porque se juega como se vive. \\ Ariel Magnus
}

\section{Introducción "satelital": no al dejà-vu}

A nivel fenomenológico, la desaparición forzada de personas bajo la última dictadura militar argentina (1976-1983) es un hecho radical y, a la vez, dicótomo que no sólo dificulta los procesamientos jurídicos y arroja al vacío las opciones de representabilidad ética y simbólica; sino que en el campo de la estética pone particularmente en cuestión los dispositivos de representación visual y su presunta capacidad de comprobación y verosimilitud. Desde un principio, los medios estéticos que se aplican a la inventiva de re/presentar lo depresentado se explican ex negativo. La desaparición, categoría espectral, hace por lo tanto tan urgente el trabajo de las Comisiones de la Verdad y de la Antropología Forense; éstos enfrentan a la aisthesis de lo unheimlich con la materia. También el arribo de la desaparición al cine implica

1 Este artículo tiene su origen en una ponencia del mismo título; a la vez representa el cut-out de una tesis de doctorado (Antidepósitos: SubVersiones mediáticas de la desaparición paradigmática en la producción estética de la generación HIJOS (1996-2006)). Esta indaga en las específicas opciones que poseen los diferentes medios para encarar la depresentación que causó el secuestro y el asesinato de las aproximadamente 30.000 personas en Argentina a partir de 1976. Los y las agentes de las estrategias estéticas analizadas pertenecen a la generación HIJOS y se valen de los medios de una forma marcadamente generacional para evitar que el trauma acontecido en un tiempo ideológico ahora histórico, se "deposite" y caiga en el olvido. Sus subversiones mediáticas hacen patente tanto el aspecto instantáneo, transfronterizo y plural de los nuevos medios como el aspecto performativo de una contracultura mnemotécnica inspirada, en parte, en aquella de las Madres de Plaza de Mayo. Simultáneamente, recurren a la estética que sembró la vertiente postmoderna de la producción cultural argentina. A continuación se enfocarán algunos de estos requisitos. 
que el "fenómeno" se encuentre con un soporte material: el celuloide y los artefactos de grabación y proyección. Esta tensión entre lo depresentado y los dispositivos mediales, que además significan una propia dinámica de la desaparición, producida por el desenrollamiento veloz de las imágenes cinemáticas, se distingue del reto que experimenta la literatura, ya que se lleva a cabo en un campo conectado con la producción industrial, la cultura de masas y con los mecanismos de la sugestión, elementos que influyeron en la construcción de las dictaduras modernas. ¿De qué forma, específica, denuncia el cine estos principios y cómo trata la ausencia causada por el terrorismo de estado? ¿Qué muestra el cine argentino de la desaparición, qué conserva como inmostrable, hay formatos establecidos, dejà-vus de lo invisibilizado, 25 años después del fin del régimen? ¿Son asumidos estos cuestionamientos a nivel generacional? Las dudas mencionadas rebasan las posibilidades de este artículo, menos la última. Valga indicar que Wikipedia ofrece un corpus de manifestaciones sobre las dictaduras latinoamericanas de la Guerra Fría, y que el cine argentino corre con buena parte de estos "gastos" culturales. ${ }^{2}$ Entre las obras listadas, documentales y ficcionales y producidas desde 1985, se encuentran: La república perdida II (1986), La historia oficial (1985), La noche de los lápices (1986), Sur (1987), Verónico Cruz: La deuda interna (1988) y La amiga (1989). A partir de 1995, una generación intermedia de cineastas lanza obras como Buenos Aires viceversa (1996), Garage Olimpo (1999), Figli/Hijos (2001), Los pasos perdidos (2001), H.I.J.O.S., el alma en dos (2002) o Kamchatka (2002). Con el comienzo del nuevo siglo la generación HIJOS, sobreviviente y a su vez "desaperecida" de sus madres y padres genéticos o de sus antecesores simbólico-culturales, hace aparecer obras como Sol de Noche (2002), Cautiva (2003), Nietos (Identidad y Memoria) (2004), Hermanas (2004), Buenos Aires 1977/Crónica de una fuga (2006). ${ }^{3}$ Inventarizada por una nota periodística bajo el rubro "Los chicos crecen" (Página/12 2005, sin autor/a), esta generación se caracteriza por la inscripción bio-histórica de la ausencia sin haber vivido el trauma "en carne propia", y por cierta distancia a la ideología que movilizó a

2 Cf. la lista de enlaces al final de este artículo. Cf. además Amado (2009).

3 Para los datos específicos de las obras cf. filmografía al final de este artículo. 
los ahora muertos. ${ }^{4}$ En cambio sí recurre a algunas preliminarias estéticas planteadas por éstos; además, está marcada por el declive neoliberal en 2001/02.

Albertina Carri ofrece una de las perspectivas más insólitas de este conjunto generacional. Su film Los rubios, de 2003, se abre camino en el vasto campo de la memoria, en el cual los medios mnemotécnicos entran en competencia y corrientes hegemónicas deciden lo que es memorable y lo que no. El presente artículo analiza la extraordinaria puesta en escena de lo insondable que ofrece Los rubios legitimándose frente a lo fantasmagórico con un discurso y una práctica de la desconfianza. Carri compensa el vacío con la materialidad, inclinándose al teñido y la sustancialidad física de un pasado traumático y logra con ello un split entre el shock y el kitsch de la historia. Su airoso ensayodocumental rompe con cualquier dejà- $v u$ de la desaparición en el cine argentino, por desarollar una "magia multigénero" en parte radicada en secuencias stop-motion con figuritas Playmobil. Este reality show (Gorodischer en Moreno 2003) de la memoria post-orgánica, salida de un cuarto infantil, garantiza no sólo una vitalidad irritante. La miniaturización incita además a una especie de tele-visión o perspectiva satelital que relativiza toda emotividad establecida ante las catástrofes históricas: Stop emotion.

\section{El nuevo formato de la memoria de Los rubios: "todo eso, y mucho más"}

Albertina Carri, hija de Roberto Carri y Ana María Caruso, ${ }^{5}$ nace en 1973. Sus padres "desaparecen" en 1977, pasando por el centro clandestino de detención El Sheraton.

4 Esto vale también para las implicaciones ideológicas del cine: el nuevo cine argentino no es comparable, ni tiene que serlo, con el compromiso del "Tercer Cine" marcado por Fernando Solanas y Octavio Getino.

5 Roberto Carri fue escritor, docente y periodista con una importante lista de publicaciones, entre ellas Isidro Velázquez: formas pre-revolucionarias de la violencia (1968); Ana María Caruso fue profesora de Letras. Ambos eran peronistas y se unieron a la organización Montoneros. Fueron secuestrados el 24 de febrero de 1977. Sus hijas Albertina, Andrea y Paula fueron llevadas al campo, donde crecieron con una parte de su familia. 


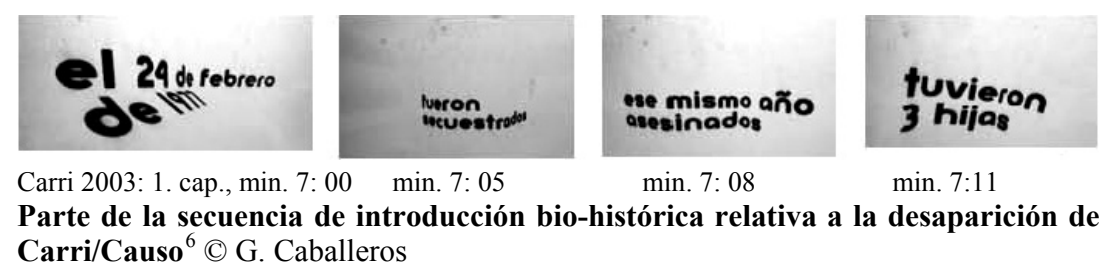

Egresada de la Universidad del Cine de Buenos Aires, Albertina Carri inicia en 1998 su primer trabajo de dirección, el largometraje No quiero volver a casa, que se estrenará en 2001. Tras realizar y participar en varios cortometrajes, como Aurora e Historias de Argentina en Vivo (ambas 2001), en 2003 lanza Barbie también puede eStar triste, un porno de animación. En el mismo 2003 tiene su estreno Los rubios; en 2005 Geminis, en 2008 La Rabia. La obra de Carri enfoca de forma acentuada las estructuras familiares y los procesos de individuación, diferenciación y enajenación, también violentos, que tienen lugar en ellas: No quiero volver a casa cuenta cómo una prostituta se vuelve eslabón entre dos familias atravesadas por un asesinato; Geminis vuelca su mirada sobre la soberbia burguesa, haciéndola desembocar en el incesto; La Rabia ofrece un cuadro de panoramas familiares ubicados en un hostil entorno pampeano, donde una infantil protagonista muda desarrollará una relación mimética con la bestialidad de su medio ambiente natural.

Los rubios es hasta ahora la obra más celebrada de Carri. Con una trayectoria de producción dificultada, a lo largo de la cual el Instituto Nacional de Cine y Arte Audiovisuales (INCAA) en un primer momento le negó al film los respectivos subsidios oficiales por una supuesta "incoherencia" del guión, lo primero que hace Los rubios es justamente relatar su obstaculización. Este encuadre hará patente los mismos mecanismos de "represión" - o de reglamentación-impartidos por las instituciones culturales y sus programas de apoyo y facilitación. Sin ir más lejos, en este sentido Carri plantea una especie de rito de iniciación programático para Los rubios: el de un fracaso productivo. Con ello, alude al poder mnemotécnico de las canonizaciones, ya que al mencionar el juicio del INCAA señala, en teoría, que el film

6 Este artículo conjuga un discurso de ciencia cultural con algunas referencias icónicas. El número de los screen-shots elegidos de Los rubios es limitado y no puede ser analizado de forma cinematográfica. 
hubiera bien podido no ser realizado. La gran repercusión de la docuficción -recibida con entusiasmo en el Festival Internacional de Cine Independiente de Buenos Aires en 2003-enfatiza, no obstante, que este enunciado cinemático de incongruencia deseada es justamente lo que merece entrar en el cuerpo plural de la memoria social. Dando fe de la subvertibilidad de un "guión" hegemónico respecto a lo que debe y cómo ser contado y visualizado de las múltiples historias provocadas por los tiempos de plomo en Argentina, Los rubios ha sido valorado como un nuevo paradigma imaginario de la dictadura: “¿Pero qué es Los rubios? ¿Un documental testimonial, un largo de ficción, una autobiografía? Es todo eso, y mucho más" (Molinero 2003).

\section{3. "Ejercicio pasoliniano" y Tableau Vivant - Los rubios, inestables e incontrolables}

En primer lugar, Los rubios se ha ganado la consideración de la crítica periodística y académica argentina y estadounidense, ${ }^{7}$ circunstancia poco fortuita que testifica los datos de co-producción del film, a saber argentino-estadounidense. Entre los numerosos comentarios algunos le adscribieron a la obra un estilo extraño y "testarudo", también por su estructura diáfana e híbrida o mudable, al menos estrictamente noprefabricada:

[Los rubios] is not so much a documentary as a fictional film about the making of a documentary, or perhaps a documentary about the making of a fictional film about the making of a documentary (Scott 2004).

Otras voces subrayan el tinte "absurdo", pero también "trágico" e inclusive cómico del film (Hagopian s.d.). Efectivamente, Los rubios no se refiere a los desaparecidos ni en términos de solemnidad ni de mitologización, sino que se limita a detectar las huellas y lagunas que dejaron y conlleva las en parte contradictorias o paradójicas versiones subjetivas de la memoria. Como se verá más adelante, este factor le prestará a la obra el título. ¿Mas será el trabajo de Carri precisamente

7 Algunos de los estudios, en gran parte considerados por este artículo, coinciden con éste en varias observaciones, como el de Cecilia Macón sobre la estructura traumática o el de Martín Kohan relativo a la dinámica del desdoblamiento. También los trabajos de Amado y Garibotto/Gómez asombraron por sus argumentaciones casi paralelas. De tal forma, el trabajo centrará su eje hipotético en la temática del Playmobil. 
un "ejercicio pasoliniano"? (Cancela 2005). Pasolini trabajó a menudo con actores no profesionales; en Los rubios Carri logra una duplicidad de sus figuras confundiendo la puesta en escena de éstas con la presencia de quienes hacen el film -incluyéndose a sí misma-. Con este arreglo, quizás pararealista, logra que el film fluctúe entre la profanización y la trascendencia, es decir que los y las integrantes de la obra cubran un papel tanto documental como ficticio y simbólico. La marca alegórica de esta estrategia es la dupla constituida por Carri y la actriz Analía Couceyro, que en su papel adopta un aire documentalista exponiendo a su rol tal cual (Carri 2003: min. 7:18-20, en YouTube 2007: min. 0:32-0:35). El desdoblamiento y la alternancia hacen que la instancia denominada "Yo" se recalque como categoría inestable, transferible. La "auténtica" Carri se conjuga con Couceyro, ${ }^{8}$ que le es fiel a su actuación, reemplazante de Carri, lo cual hará del contexto, desde el cual la directora ejerce su acción, una "autenticidad" reemplazable por un orden ficticio. Los rubios, entonces, podría ser visto como la puesta en marcha de un tableau vivant de la existencia de Carri, tanto como la vida de Carri, o al menos un extracto de ella, es Los rubios. Conforme a la compenetración de presencias, alcanzada por la explícita performación en equipo, el Yo de Carri se vuelve Yo plural, con lo cual en el fondo se relativiza también la autoría del film. Los rubios es un gabinete en el cual se libra el combate por la adecuación de palabras y gestos que des/re/armen el pasado, sin preceptos auctoriales. Por lo demás la lógica del doble se perpetúa a nivel medial, ya que el film muestra la simultánea acción de diferentes cámaras que harán una labor particular ${ }^{9}$ sin dejar de compartir su medialidad.

8 Hablando en términos psicoanalíticos, el film inclusive se entrega a la desrealización y despersonalización. La desrealización es registrada por el ICD 10 (F 48.1) de la Organización Mundial de la Salud como un síntoma relativo a los "trastornos del Yo". Se caracteriza por una alteración, un desfase o una agudización de la percepción del entorno de una persona (sinestesias, sensación de artificialidad, falta de o aumento del sentido cromático, etc.), representando un avatar del concepto filosófico de la enajenación. Su contraparte se da con la "despersonalización", que distorsiona la percepción de la integridad física como mental del sujeto que la sufre. Ambas experiencias, a las cuales Los rubios parece remitir en su estética, pueden resultar tanto de un episodio traumático, como ser causados por meditación, falta de alimentación y sueño o ser inducidos por substancias psicotrópicas.

9 El material que compone la histoire está en color, la grabación de ésta tanto como los debates que se llevan a cabo durante la filmación, (en su mayoría) en blanco y 


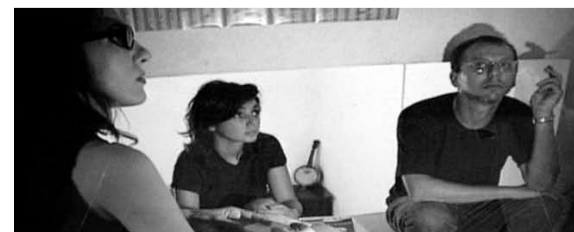

Parte del equipo de Los Rubios

Carri 2003: 3. cap., min. 27:04

\section{Standing supervivencial, "clic de vida": el laboratorio del trauma}

Partiendo de la ausencia de sus padres, Carri expone un lugar cero biográfico radicalmente existencial: un anti-mito ${ }^{10}$ de iniciación, que sella la llegada a la conciencia con una pérdida definitiva e indemnizable. Su relato de vida funciona ex negativo; no puede ser canonizado por la mitología de formación burguesa. Pero Los rubios tampoco cumple con las mitologías reclamatorias de una "reaparición con vida" de los ausentes, no pretende reparación. Al contrario: más aún que en la fractura, el film se centra en el hecho de la desmaterialización como un proceso biográficamente asumible. La vida de Carri y sus hermanas es definida por la desaparición de los padres, pero también por la integración de lo depresentado. El film se abstendrá de mostrar documento visual alguno de la pareja Carri/Caruso, activando y promoviendo en cambio la presencia y el presente de las hijas Carri.

El standing supervivencial de Carri es paradigmáticamente generacional. Según las divisas anotadas por el periódico $M U$ respecto a la generación HIJOS y como sostiene también Naomi Klein, Carri, sin miedo, produce "un clic de vida asombroso", "pone el cuerpo" y se aplica a "la tarea de construir la propia identidad y reconstruir la de sus padres" (Klein en anón. 2008/2009: 3-4). Sin embargo se distancia de categorías morales como la vergüenza y la culpa (Feierstein en anón. 2008/2009: 5) que definen prácticas sociales como el "es-

negro. Luego se transfieren también entrevistas grabadas por vídeo hacia diversas pantallas, que, experimentando un mise en abîme dentro del film, serán contrastadas por los comentarios del equipo y los documentos bio-históricos de las hijas Carri.

10 El mito es entendido aquí como relato existencial que enfrenta los contrarios que se supone constituyen a la existencia misma, pero con el fin de apaciguarlas o por lo menos de domarlas, ofreciendo una narración sagrada, maravillosa o al menos "redonda" de ellos. 
crache". Plasmando su pleito por la democratización de la memoria más bien en la renovación de las estrategias formales, Los rubios se distingue justamente por su enfrentamiento técnico del trauma, que tiene en cuenta la suposición de que la dictadura siga "sucediendo para siempre" (Link en anón. 2008/2009: 10). Caracterizado, a nivel sintomático/"patológico", por disociar al aparato psíquico de la sensación agresiva, el trauma encuentra su "malicia" en el hecho de que no deja de emanar su significado destructivo aún en la situación posttraumática; en el contexto de persecución política, detención y tortura, el síntoma post-traumático se vuelve entonces síntoma de una historia inacabada. Por lo tanto, Carri da en el blanco del trauma y de la memoria imposible, cuando hace de su film un cuadro laboratorial, un antimonumento.

\section{Antimonumento: desenterrar imágenes/extraer sangre, como la memoria misma}

Tomando registro del soporte que brindan tanto la filmación misma como sus diferentes productos (o sea las grabaciones de vídeo incluidas), y prescindiendo de cualquier apelación elevadora y oficialmente conmemorial, Los rubios hace hincapié en ser un documento transparente y en construcción que, como la memoria misma, se basa en un gran porcentaje de no-saber sobre el pasado. Consecuentemente, Couceyro anotará en una cartulina:

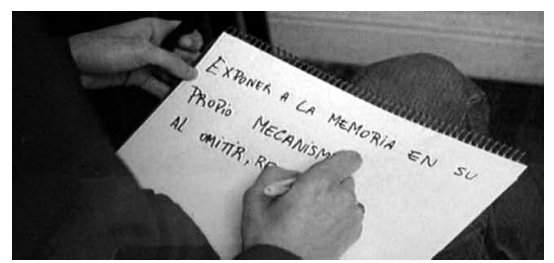

"Exponer a la memoria en su propio mecanismo [...]"

Carri 2003: 2 cap., min. 14:47

(C) G. Caballeros

El film le será fiel a este manifiesto, haciendo hincapié en la dinámica de la producción de las imágenes, como si se tratara de los mismos dispositivos del recuerdo subjetivo/orgánico, ${ }^{11}$ cerebral: Procesa las

11 Más allá de que el término es aquí empleado en el sentido de "no-digital", cabe recordar que se deduce de la voz latina órganum, que quiere decir "herramienta" e "instrumento". Véase también el cortometraje Me moria de una de las integran- 
grabaciones del pasado en un espacio de almacenamiento y proyección visual, pero a la vez los refuta, los desplaza y reemplaza.

Otro aspecto extraordinario de Los rubios es el siguiente: El film incorpora un segundo soporte visual tanto documental como simbólico: la fotografía. Centrará su atención en una imagen enmarcada de la cual se supone que la persona que la tomó sufrió tortura. La afirmación será verificada y Los rubios invoca a que se recuerden las hipótesis centrales pronunciadas por Susan Sontag: que la fotografía/la cámara no es solamente un medio anclado en la veracidad, por un lado, y en la pseudo-experiencia, por otro, sino también en la muerte misma (Sontag 1977; 2003). Efectivamente, al contemplar la foto Carri/Couceyro se cuestiona si la cámara tiene parentesco con la picana o con el hacha con la cual se mata a las vacas; ${ }^{12}$ luego, la autora de la imagen resulta ser la única sobreviviente de El Sheraton.

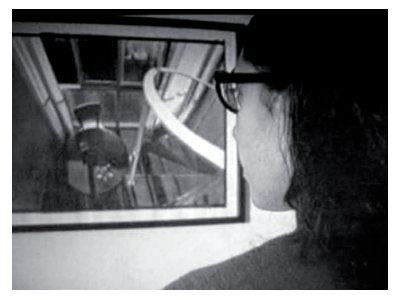

Couceyro contempla y comenta la fotografía mencionada

Carri 2003: 5. cap., min. 49:16 (C) R. Bolte

Este ex-centro clandestino de detención ${ }^{13}$ es la última estación física registrada de la pareja Carri/Caruso. Mientras que Los rubios omite fotografías que muestren a la pareja, aludiendo al (también) vacío no solamente de la imaginabilidad fílmica -secuencial- sino a la vez a

tes de la unidad de cámara de Los rubios, Paola Pelzmajer, que visualiza este procedimiento y a la vez lo connota con la mnemotecnia de los artefactos como el contestador automático (Pelzmajer 2006).

12 El film consta de varias secuencias que muestran vacas, sobre todo jóvenes, que son vacunadas y llevadas a los corrales. Las tomas hacen imaginar las futuras escenas del matadero; además le siguen a las tomas de una ilustración gráfica que hace Couceyro de las celdas de El Sheraton (cf. Carri 2003: 6. cap., min. 54:24$40,55: 41-55$ y $56: 20-28$, y otras).

13 El Sheraton, localizado en el barrio La Matanza, funciona hoy como comisaría (cf. Carri 2003: 2. cap., min. 16:00-17:00 y 7. cap., min. 1:0:08-09:20; el relato de Couceyro sobre cómo el equipo de filmación fue tratado en este lugar: Carri 2003, 2. cap., min. 18:28-19:06). Para una enumeración de los ex-centros clandestinos de detención (CCD) cf. lista de enlaces. 
aquella de la instantánea, fotográfica, Carri se aventura a la ubicación y filmación del lugar en el cual se inició la desaparición definitiva de sus padres. A este rastreo se suma un sondeo de los micro-códigos de la memoria postdictatorial argentina: la genética. Una escena muestra una extracción de sangre, precisada para el análisis del ADN, que forma parte del trabajo del Equipo Argentino de Antropología Forense (EAAF). ${ }^{14}$ Las exhumaciones de cuerpos hallados tras la dictadura se iniciaron paralelamente a las documentaciones de la CONADEP. Hoy forman un pilar concreto, material y científico para las investigaciones sobre la desaparición. El trabajo del EAAF consiste, por un lado, en la identificación y recuperación de hasta la fecha 30 cuerpos. Esta tarea necesita de la consideración e "inspección" de la información genética de los vivos y sobrevivientes - como la de Carri-. Llevada al terreno del cine, esta rama de la antropología dialoga, desde su praxis científica, ${ }^{15}$ con los métodos de inspección y rehabilitación de los sistemas de representación simbólica y/o documental (Carri 2003: cap. 3, min. 20:00-22:55, en YouTube 2007: min. 43-52). Consecuentemente, el punto de vista de Carri de repente sí es infiltrado por el status de la lastimada, o por lo menos la afección, detectada por la objetividad científica, determina la estética de su film durante unos momentos. La escena de la extracción de sangre figura como punctum (Barthes 1980), ${ }^{16}$ como détail poignant, de lo cual da cuenta la huella del tono. La secuencia apaga las voces, y las sustituye por un sonido como de viento, relativizando, definitivamente, el calibre de la memoria monumentalizante. Los rubios combina un lenguaje de la fractura con la inserción de "moléculas mnemotécnicas": la memoria de la sangre. El fluido vital, salido de las venas de Carri, es un elemento/medio en el cual se depositó la afiliación con las víctimas de la represión política,

14 Por lo demás, la tarea de este equipo significa también la rehabilitación del trabajo forense, que bajo la dictadura fue una tarea dependiente del régimen. Para la página del EAAF cf. lista de enlaces.

15 Esta tiene también su vertiente icónica. En la oficina de la EAAF Carri/Couceyro contempla láminas con ilustraciones de calaveras y esqueletos humanos (cf. Carri 2003, cap. 3, min. 20:56-21:03).

16 El punctum en La chambre claire de Roland Barthes es un lugar del "shock" a nivel de la recepción de la fotografía. En la imagen misma representa un lugar de fisura, que requiere gran parte de la atención emocional de quien la mira y menos el gusto estético (que equivaldría al studium). El punctum está más allá del lenguaje: es puramente 'evidente'. 
que, una vez comprobada, será de importancia social, política y jurídica y entrará en el corpus de trámites que intentan verificar los crímenes cometidos por la dictadura. Pero ojo: en un primer paso el film recurre a la sangre de Couceyro y luego a la de Carri (Carri 2003: cap. 3, min. 21:49-22:00, sigue Carri, en blanco y negro: min. 22:0622:32). La examinación de los eslabones microscópicos de la vida es por ende desplazada, y Los rubios le hace prueba al extracto vital de la familia Carri de forma metafórica, creando un "estado de alerta" (Garibotto/Gómez 2006: 111) en torno a cualquier tipo de acreditación.

El dictamen del INCAA arguyó que el guión de Los rubios debía ser revisado "con mayor rigor documental", y que el "destino trágico" de los intelectuales comprometidos que fueron Carri y Caruso merecía un trabajo más exacto (Carri 2003, cap. 3, min. 25:16-26:18). El Instituto juzga desde un lugar generacional, identificado con la pareja desaparecida (cf. el debate sobre esto en Carri 2003, cap. 3 min. 26:2028:37, screen-shot $\mathrm{n}^{\circ} 5$ ), que al parecer de la institución queda sin rostro por error. Pero Albertina Carri explica en una entrevista con Página/12 que quería evitar el efecto tranquilizador de los testimonios y reforzar la inaprehensibilidad de sus padres (Garibotto/Gómez 2006: 119). Por tanto da un paso más. Disimula apostar por la voz del intelectual Roberto Carri para compensar la extracción de su vitalidad biológica: Couceyro recitará partes de un escrito del sociólogo. Esta aparente instancia perdurable, empero, es un fake (Garibotto/Gómez 2006: 119; Kohan 2004), y Roberto Carri, para que no quepa duda, nunca más será atrapable.

\section{La materialidad de una época o la docilidad del Playmobil}

Pese a su acento no-monumental, Los rubios visualiza las monumentalizaciones levantadas por la dictadura, como las autopistas y los lugares urbanos panópticos. ${ }^{17}$ Carri, por lo pronto, revela que en el transcurso de la historia pueden volverse área para nuevas inscripciones: tanto los títulos de crédito del film como otros dispositivos ya mostra-

17 Véase el screenshot de Couceyro con peluca, escena rodada en una de las plazas prototípicas, bien controlables, en Buenos Aires. 
dos se presentan en estilo stencil, ${ }^{18}$ y provocan la impresión de que la misma materialidad de una época -asfalto, concreto- formara el portal del film, pero siendo poblado por mensajes renovados.

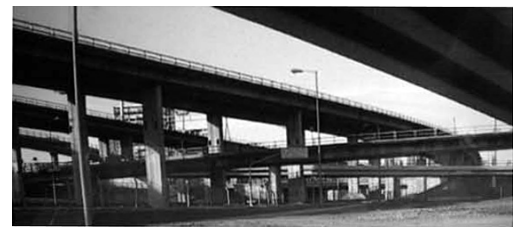

Carri (2003: 2. cap., min. 15:52)

Autopista urbana (C) G. Caballeros

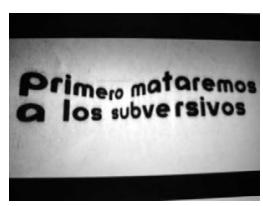

Carri 2003: 6. cap.,

$\min .55: 56$

Parte de una secuencia de stencil con la "famosa" cita del General Ibérico Saint Jean $\subset$ R. Bolte

Los nuevos mensajes, sin embargo, se asientan sobre la base histórica, que consiste por ejemplo en los ex-espacios concentracionarios como El Sheraton. Los rubios yuxtapone tomas de estos lugares con tomas de los ex-"corredores" de la persecucción. ${ }^{19}$ Pero el film amaña su golpe más ingenioso intercalando este registro de la signatura de los años 70 argentinos con secuencias de animación en las cuales muñequitos Playmobil, ya desde la apertura del film, figuran en una especie de mapeos topo y escenográficos en miniatura. El recurso del desdoblamiento y el desplazamiento cubre aquí otro horizonte material más. Los Playmobil son elementos de refacción, piezas de repuesto de lo perdido. Cual mini-réplicas arman una coreografía infantil de los sucesos provocados por la dictadura y se encargan a la par de reconfigurar el panorama de una vida social utópica que le precedió (Carri 2003, cap. 5, min. 42:05-40):

18 El stencil es un tipo de graffito que se sirve de plantillas. Las respectivas secuencias serán, en el fondo, un arreglo digital, pero disimulan la apariencia de los graffiti.

19 Con razón: recuérdese el ex-centro clandestino de detención Club Atlético en Buenos Aires, en el predio debajo de la autopista urbana en San Telmo, Paseo Colón, a la altura de San Juan y Cochabamba. En el Club fueron desaparecidas más de 1.500 personas. En 2002 se inició la excavación y en 2003 se creó un programa de recuperación de la memoria del lugar. Para más detalles cf. lista de enlaces. 


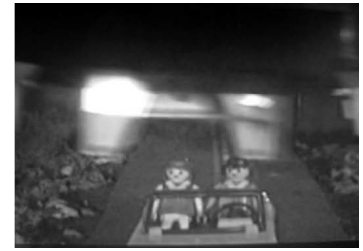

Carri 2003: 5. cap. , min. 42:23

Fiesta Playmobil antes de la desaparición

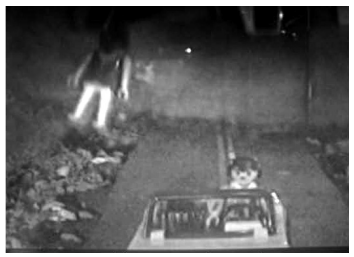

Carri 2003: 7. cap., min. 1:02:31 min. 1:02:33

Secuestro por ovni Playmobil, después de la fiesta ${ }^{20}$

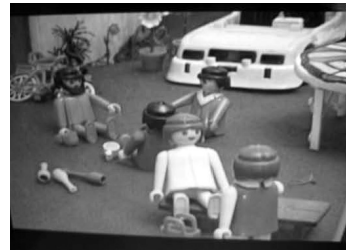

C R. Bolte

Los rubios alude aquí a la cultura social alternativa que fue desaparecida y la ensarta en el hilo lúdico que hace del Playmobil la seña cultural de un período industrio-cultural y político, y un marcador de la tangibilidad y el colorido de la infancia de las hijas Carri. A la par, las figuras intercambiables y manipulables de Playmobil se adecuan a la reflexión del film sobre la arbitrariedad y la violencia de las construcciones de identidad y diferencia. En una serie stop-motion a cámara rápida, acompañada por un discurso teórico, los prototipos de cabezas ingenuas y peinado tipo casco cambian vertiginosamante su aspecto (Carri 2003, cap. 3, min. 28:56-29:28). Los rubios reviste aquí un terreno benjaminiano, marcado por despojos e invisibilidades, con una propia escritura plástica/de plástico. Al igual que algunos largometrajes que atisban la vivencia infantil de catástrofes históricas como Holocausto/Shoah o la Guerra Civil Española - La vita è bella (1997), El laberinto del fauno (2006)- y los films argentinos Kamchatka (2002) y La cara del ángel (1996) - la obra de Carri demuestra que esta tentativa está impregnada de momentos fantasiosos, a su manera significativos.

Carri legitima su opción estética y discursiva con las siguientes palabras: "A mi me interesaba hacer esta película no para hacer catarsis, sino porque con las otras películas que abordaban el tema no me sentía representada" (Carri citado en Cancela 2005). El por lo menos "psicodramático" efecto de Los rubios se basaría entonces en una especie de ensayos (para)catárticos, ya que no cabe duda de que el

20 A estas tomas le siguen unas secuencias con Playmobils infantiles: tres nenas rubias caminan por la misma ruta campestre; antes se muestra, durante un segundo, una muñequita morena, también secuestrada por el ovni (cf. min. 1:02:56-59. Además véase la puesta en escena de la pareja Carri/Caruso como Playmobils: Carri 2003: 6. cap., min. 57:57-58:13). 
film toma posición ante objetos trágicos. Pero antes de responder a ellos, los coloca de forma nueva, distanciadora, sirviéndose de las coordenadas experimentales del film. Y aunque no parta de la categoría del espectáculo y su intención (catártica) de dar lástima o causar horror, sí llevará a cabo una abreacción. Sin embargo ésta es laboratorial, materialista, y satelital. Los satélites orbitan alrededor de un sistema que observan o controlan, son guardianes y espías artificiales, medios de comunicación que tras su misión frecuentemente terminan como basura espacial. En Los rubios, se sondea el pasado echando una mirada, en parte, sobre un panorama de miniatura especialmente confeccionado. Este acercamiento, fiel a cómo se entiende la abreacción freudiana, ya devela a las cámaras como vehículos en un "juego alegre" mediático; luego inclusive convoca a un ovni. El "objeto volador no identificado" apunta a la abyección (Kristeva 1980) ${ }^{21}$ y a lo unheimlich del "entrar en juego" de la historia. Finalmente, las figuras Playmobil son identificables como módulos de una simbología de masas y "unidades colectivas" (Meueler 2009; Canetti 2001), como avatares protéticos que no únicamente adquieren, cual juguetes que radican en un fin en sí mismos, vivacidad en las manos de quien los agarra. Ante todo funcionan como médiums de proyección y socialización cumpliendo con el papel de muñecos vudú sintéticos con los cuales Carri equipa su mirada distanciada sobre lo que perturba su identidad y su infancia (abyectada). El muñeco vudú sirve como catalizador para perjudicar o, al contrario, para salvar desde lejos a alguien que simboliza en miniatura. En Carri los Playmobil cumplen con la función de catalizar de forma metafórica el proceso de internalización de normas y formas de percepción y desaparición de la realidad. La vista satelital producida por el mero tamaño de los agentes primitivos, convierte a las cámaras en guardianes y espías con alcance retrospectivo. Para profundizar este eje hipotético, valga esbozar un perfil histórico-cultural del Playmobil. En su artículo "The dark ages. Rein-

21 Kristeva (1980: 12) entiende bajo abyección 'lo que perturba una identidad, un sistema, un orden'. En términos más amplios, la abyección significa la exclusión de un orden (simbólico). Aquí es entendido como concepto psicoanalítico, según el cual se acopla con la categoría de lo unheimlich, elaborado por Freud en torno a la literatura fantástica (de E.T.A. Hoffmann). Sin poder profundizar este planteamiento de lo siniestro, valga indicar que la abyección es una reacción a ello, un distanciamiento cognitivo y/o estético frente a lo inquietante. 
venting Playmobil for modern times", Kate Muir observa: "That's the thing with Playmobil - it allows your imagination to run free in unhealthy ways" (Muir 2008) Aunque Carri no busque sanación, tampoco parece "insano" lo que hace con el Playmobil. Aunque la empresa productora de éstos juguetes, Geobra Brandstätter $\mathrm{GmbH}$, aparentemente haya intentado evitar que el cosmos Playmobil sea saboteado por la violencia y el horror (WIN 2004; Bachmann 2004), la toy line ha incitado a la formación de una considerable comunidad de coleccionistas (Hennel 2009), que en su gran parte ha trasladado sus figuras al terreno del miniature wargaming. ${ }^{22}$ Entretanto, su acogida en el área de las representaciones simbólicas se da con la aparición de series fotográficas y películas stop-motion. Una búsqueda en YouTube conduce a incontables cortos de animación protagonizados por estos dóciles y ajustables muñequitos, de los cuales un buen número son películas de horror. La película de Carri, entonces, forma parte de este universo -sin pertencer a la genérica película de horror, pero sí tratando de un horror histórico-.

El presunto Kindchenschema de los Playmobil no es incontaminable: Ya su nacimiento tras la crisis petrolera en 1973, aún bajo el nombre "Klicky", marca una coyuntura, el significante advenimiento de un past war-toy alemán, en el cual sí están inscritos los traumas de una sociedad postdictatorial. Hans Beck, "padre" de los Playmobil, describe la impotencia y la cobardía como una experiencia básica de la infancia, mientras que Meueler, a su vez, advierte que los Playmobil parecieran, desde su principio anatómico, reclamar que algo les sea dado en las manos, preferentemente un arma. Respondiendo de tal forma a la necesidad de invertir y procesar la debilidad infantil, el Playmobil se convierte en un "mundo paralelo" (Meueler 2009). "That's the thing", entonces, made by Carri con los Playmobil: Los rubios monta settings que atestiguan la capacidad del juguete de cobrar vida propia, como si se tratara de reemplazar al Cascanueces. De hecho, las secuencias de animación poseen un aura fantástica, aunque el setting Playmobil fuera ante todo políticamente y socialmente avateresco o protético. ¿Desplaza Carri su procesamiento de lo inaprehen-

22 Cf. la lista de enlaces a las respectivas fan sites al final de este artículo, en las cuales se subraya que Playmobil se presta sobre todo para los settings de guerras históricas (batallas medievales, romanas y egipcias, etc.). 
sible no sólo valiéndose de ayudantes de aprendizaje, sino además de alegorías cosificadas, y se abisma hacia el fetichismo? Las maquetas Playmobil son respuestas sustitucionales a la inquietud que despierta el contacto con lo irrepresentable. Este temor se amalgama con la necesidad de imaginar un capítulo de la historia argentina que se caracterizó por la economía de la exclusión y estigmatización. Los Playmobil aquí son piezas ideales, y dejarán el cosmos de lo inanimado para adentrarse en la animación como protéticas "unidades colectivas" canettianas que recordarán la política de la alteridad bajo la dictadura y el sello del "enemigo interno". Pues sucede que igualmente el Playmobil, este producto de trascendencia mundial con 2,2 millardos de ejemplares vendidos, ${ }^{23}$ no es solamente apto para el travestismo y, con ello, un "efectivo transmisor de identidades" (Meueler 2009), sino también un productor de otredades. Con este recurso Carri siembra su propia duda sobre la gestión de las identidades, tanto en tiempos de represión y clandestinidad como en tiempos "post", en los cuales la lucha por las diferencias es un nuevo desafío en Latinoamérica. En 1985, Playmobil intentó lanzar un modelo esquimal, que más tarde se tuvo que convertir en Inuit. Apenas sobrevivió.

Para concluir: Los rubios entra en el mercado de las producciones culturales sobre la historia argentina inmediata valiéndose de la materia prima de un aparente objeto profano de la infancia (Agamben $1979 ; 2005)^{24}$ para reciclarlo en un setting y resetting de constelaciones histórico-políticas.

Lo "moderno es arte por la mimesis de lo endurecido y extraño" (Adorno [1970]: 39). ¿Da Los rubios en el clavo de esta suposición? Valga constatar que lo extraño en el film de Carri radica 1. en lo que

23 Mencionado sea de paso la existencia de una explícita variante argentina del Playmobil, bajo licencia en Antex, empresa que agencia la venta del producto en toda Sudamérica.

24 En su escrito de 1979 Agamben se entrevista con la infancia como categoría filosófica basada en un entrecruce de experiencia, juego e historia. La escritura ensayística de Agamben lleva a que tópicos, como la destrucción de la experiencia, la relación de juego y ritual sean meramente rozados, lo cual hace de la publicación un mismo taller de hipótesis también acerca de la infantilidad humana, la experiencia preverbal, un principio "natural" del ser humano, a considerar para un estudio más detenido sobre la materia.

25 El original dice: "Moderne ist Kunst durch Mimesis ans Verhärtete und Entfremdete". 
desapareció; 2. en cómo esto invade lo que sobrevivió; 3. en cómo se entabla, desde este lugar de la supervivencia, una "masa para modelar" lo depresentado; 4. en cómo el recurso materialista (y performativo) elegido por la obra es capaz de hacer visible y palpable los escenarios y las prácticas de una época; 5 . en cómo esto, más allá de toda concepción dramática y genérica convencional, participa del intento de resguardar al menos algunos "módulos" de la historia de una infancia. Los Playmobil, surgidos de una materia industrial, reproducible, se balancean aquí hacia un lugar de lo sagrado, es decir que migran hacia lo mágico y creíble. Conforme a la naturaleza híbrida o multifacética de Los rubios esto significa, en el fondo, que esta obra sí se separa de la canonización estética de la realidad, pero no distingue las categorías de lo materialmente documentable, ni jerarquiza los materiales (sangre, papel fotográfico, plástico), ni diferencia la creencia de la incredulidad, ni lo entero de lo fracturado. No hay formato moral, ni fetichismo que exija tal segregación.

\section{Los cabellos de Mnemosina: el color de la memoria, y el look retro}

Los aspectos mencionados hasta aquí componen el extraordinario tinte de Los rubios. Pero, ¿por qué "Los rubios”? ¿De dónde el título? ¿Qué tiene que ver el color de pelo con la memoria? Albertina Carri recurre a testimonios de ex-comilitantes de la pareja Carri/Caruso. Entre estas retransmisiones se halla un testimonio grabado en el ex-vecindario de la familia Carri, el barrio de La Matanza. De él proviene el título. La declaración es dada por una señora peliteñida de azabache, locuaz, que, sin saber por quién es entrevistada, relatará escenas relativas al secuestro de Carri/Caruso (Carri 2003: 5. cap., min. 42:50-45:30). Ante todo, empero, asegura que la familia Carri fue completamente rubia (min. 45:40-44) y no se salvará de identificar este presunto rasgo como alien. ¿Qué hace el film con esta aseveración? Nada explícito ni espectacularizante. La afirmación de la vecina no es rebatida, únicamente es puesta al descubierto por la presencia real y física de las hermanas, de las cuales por lo menos dos son morenas. Sin embargo -y sin poder aquí especular sobre el significado de "lo rubio" en el contexto de las dictaduras occidentales y sus implicaciones racistas, lo suficientemente conocidas por lo menos en su caso más "prominente", 
y más allá de que uno de los más tremendos protagonistas de la desparición argentina, Alfredo Astiz, fue llamado no sólo "Ángel de la Muerte", sino también "Ángel Rubio"- la mención de los rubios en la obra de Carri tiene ante todo la función de acentuar, o de "colorear" una vez más la fragilidad o pluralidad ${ }^{26}$ de la memoria, sin juzgarla moralmente. Cada recuerdo subjetivo, así lo demuestra la vecina, es en el fondo un ensayo, seducido por los intereses del presente y siempre en peligro de manipulación como de pérdida de exactitud: sin ser "falsa memoria", será algo alucinado. Carri, por consecuencia, muestra que Mnemosina, diosa de la memoria, a pesar de su procedencia titánica, ${ }^{27}$ no puede garantizar nada.

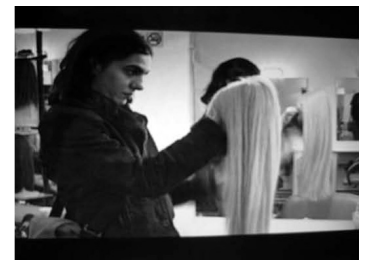

Carri 2003: 6. cap., min. 56:42

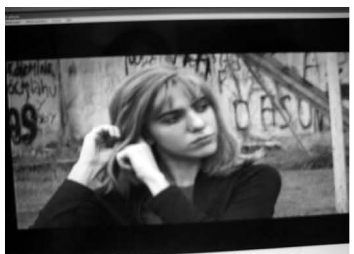

$\min .1: 01: 28$

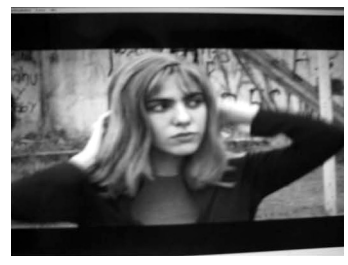

min. 1:01:34

Couceyro/Carri en varias secuencias con la peluca rubia $\subset \mathrm{R}$. Bolte

La alusión al color de pelo de la familia Carri/Caruso desembocará en una "coronación" performativa, cuando Couceyro/Carri se pone una peluca rubia. Con esta mascarada se apropiará de la des/memoria de la vecina; además el acto carnavalesco exhibe la "melena del recuerdo" como una cabellera de plástico de Mnemosina. La escena será reiterada al cierre del film. El equipo entero se pondrá pelucas blondas y realzará una usurpación camuflada de las identidades alienígenas que la vecina recuerda -o de su memoria que destiñó el "colorido" de la

26 Carri (en Moreno 2003) observa al respecto: "El hecho de que la película se llame Los rubios es [...] una verdad que yo extraigo de toda una cantidad de posiciones. Hay gente del barrio donde vivíamos que decía que mis padres y nosotras éramos rubios y otros que no" (cf. también el debate sobre esto en Carri 2003, 2. cap., min. 17:06-17:30). Además, Carri/Couceyro observará que el equipo de filmación al aprecer en La Matanza para hacer las entrevistas, es un elemento alien como en su tiempo lo fue la familia Carri/Caruso.

27 Mnemosina es hija de Gea y Urano. Su nombre reaparece en versiones mitológicas sobre ríos y fuentes que ayudan, a los que beben de su agua, a poder ejercer el arte de la memoria. 
familia de Albertina-. A continuación, Carri, junto a Couceyro y al resto del staff, dará un paso lúdico más. Como si se tratara de una banda de música pop, de look retro, el grupo rumbea hacia un horizonte hímnico, abierto, en el cual la ausencia se vuelve "esperanza" (Carri 2003, YouTube 2009: min 0:00-2:42); la obra se declina/eleva con la voz de Charly García cantando el tema "Influencia" (García 2002: $\left.\mathrm{n}^{\circ} 3\right) .{ }^{28}$ Estas escenas acontecen en el terreno campestre en el cual las hermanas Carri crecieron tras la desaparición de sus padres. Sin poder incurrir en la significante oposición de centro versus periferia del discurso argentino sobre civilización y barbarie y las narrativas de la violencia desde El matadero de Echevarría (1838-1840/1871), se ha de señalar que ya secuencias antes, y en este mismo medio ambiente, Carri/Couceyro se adentra en un bosque para dirigir un grito desesperado hacia sus padres, un "por qué la dejaron entre los vivos" (Carri 2003: 7. cap, min. 1:04:35-05:19). Esta escena, de, ahora sí, tonalidad catártica, equivale a un alarido ante la supervivencia -aunque fuera intercalado por una voz teórico-discursiva que califica esta categoría como "caprichosa"-.

La versión más conocida del mito de Mnemosina cuenta que ésta parió a las nueve musas; una versión más antigua habla de que dio luz a tres hijas. Las llamadas Mneiai incorporan en su nombre la pluralización del nombre de su madre. Una de estas hijas, Mneme, como también la madre, le presta el nombre tanto al arte de la memoria (Mnemonik) como a la mnemotecnia. Cabe proponer una lectura de las hermanas Carri como Mneiai, y de Albertina como mediadora técnica de este emprendimiento. La película sería entonces el lieu de mémoire, material y transmisorio; los Playmobil, los médiums endurecidos de la memoria moderna que integran éste en un plano paralelo; las pelucas, los (re)medios carnavalesco-sintéticos pero corporales, si bien no contra el descolorido de la memoria, entonces por lo menos contra la amnesia. Todo esto forma un equipamiento para el "look retro", para la retro-spectiva.

28 "Influencia" es un cover de "Influenza", de Todd Rundgren. Dura 5:30 minutos e integra el disco $\mathrm{n}^{\circ} 21$ de García, Influencia, de 2002. Dice: "Puedo ver y decir,/Puedo ver y decir y sentir:/ Algo ha cambiado./ Para mí no es extraño./ Yo no voy a correr,/ Yo no voy a correr ni a escapar/ De mi destino,/ Yo pienso en peligro./ Si fue hecho para mí/Lo tengo que saber./Pero es muy difícil ver,/ Si algo controla mi ser./ [...]". 


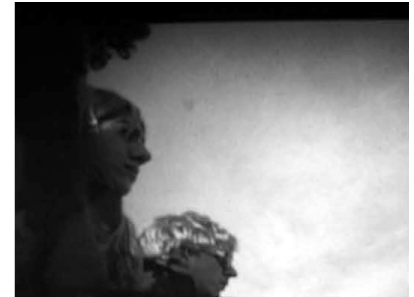

Parte del staff con pelucas, en la banda sonora el

Carri 2003: 8. cap., min. 1:16:45 (C) R. Bolte

\section{8. “Hiciste una casa?” Infantes de la memoria o las nuevas series/familias}

Los rubios abre un capítulo más en la nueva historia de la diversificación de la memoria y sus comunidades (Jelin 2002), que podría ser titulado "infantilidad de la memoria". Efectivamente, la obra de Carri incluye entrevistas de niños del mismo vecindario de la señora que marcó la sentencia sobre "los rubios". Estos niños son testigos de la conversación, pero también aportarán sus propios comentarios sobre la memoria. Las reflexiones infantiles, aparentemente a-históricas e ingenuas, se destacan de los testimonios a larga distancia de la testigo de época por parecer más ágiles. Y de repente su carencia de longue durée inspira más confianza que la memoria desteñida de la señora azabache. Aproximadamente de la edad que tenía Albertina Carri al desaparecer sus padres, los niños ejercen un impacto de identificación sutil sobre la película: representan un nuevo nivel en la escala de las memorias para la cual Carri ya preparó la base con su recurso a la narrativa sintética tejida por el elenco Playmobil.

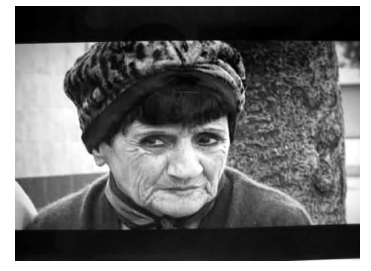

Carri 2003: 6. cap., min. 1:00:01

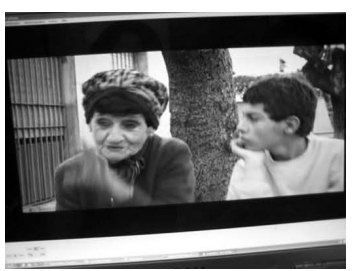

$\min .1: 00: 56$

La vecina que recuerda a

la familia Carri/Caruso como "rubia"

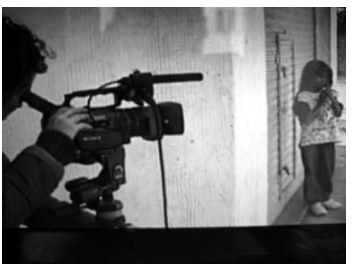

Carri 2003: 4. cap., min: 41:19

Carri filmando a una

chica del barrio

(C) R. Bolte 
Con creciente frecuencia, la producción estética de la generación HIJOS aplica la mnemo-táctica de recurrir a "emprendedores de la memoria" infantiles. En su celebrada pieza de teatro Mi vida después, estrenada en marzo de 2009, Lola Arias cita al escenario a hijos e hijas de desaparecidos para que cuenten sus vidas. Uno de ellos es acompañado por su hijo, que tiene la edad que tenía el actor cuando desapareció su padre. En una de las escenas más fuertes el niño pone en marcha un magnetofón y se escucha la voz del padre/abuelo desaparecido. Que la memoria sea un campo de combate, se debe entre otras cosas a que representa una zona de alta gravedad no sólo ideológica, sino también moral. Con la creciente labor de las Comisiones de la Verdad desde 1995 y el funcionamiento de la Corte Penal Internacional, se ha intentado definir categorías interculturales que estandaricen la inspección, el castigo y el procesamiento de crímenes estatales. ¿Se han formulado recomendaciones sobre si es válido jugar con/a la memoria o hacer escuchar la voz de los muertos en los teatros? ¿Es válido servirse de kits de refacción, de standing internacional, como el Playmobil, para "clonar" y miniaturizar las catástrofes históricas? ¿Para que todos entiendan?

En 1996, el artista polaco Zbigniew Libera provocó un escándalo cuando, con su obra Lego Concentration Camp, quiso aludir a la "racionalidad" de los campos de concentración nacionalsocialistas. ${ }^{29}$ El efecto shock que causó esta interpretación del Lego -nacido en 1949 y a su vez una toy line racional por antonomasia- se debió a que la obra superó lo que el pop-art suele ofrecer en su representación de Holocausto/Shoah (Feinstein 2000). Por otro lado Libera asoció la cuestión sobre lo que es representable y mostrable y lo que no lo es, con el poder de las miniaturas. La representación de Holocausto/Shoah en miniatura, así una conclusión del debate en torno a Libera, implica que la mirada se tiene que acercar más al panorama del horror. ¿Equivale una "micrología" de lo unheimlich a su minimización, o a su caricaturización, o es una incitación al voyeurismo? Refaccionar los dispositivos de la aniquilación recurriendo al baúl de los materiales industrio-culturales es, tras los debates sobre la holocaust industry, sin

29 La obra se expuso en la Galeria Wang en Oslo; en la Biennale de Venezia de 1997 fue suspendida. Consta de siete paquetes fictivos de un kit de Lego para la construcción de un campo de concentración, inclusive presos y personal de guardia, sala de tortura, crematorio y cámara de gas. 
duda una cuestión sensible. Las piezas que salen de la producción serial, empero, poseen un efecto hipnotizante. Teniendo en cuenta que el cine, valioso portador de discursos y visualizaciones para una elaboración de traumas históricos, se vale de materiales como el celuloide (como el Lego se basó en acetato-celuloide), de la puesta en serie de las imágenes y del efecto hipnotizante, el escándalo acerca de Libera pareciera ante todo residir en el atrevimiento de acercarse a las ya prefabricadas "tropas" reclutadas de los cuartos infantiles. Vistas como a través de un microscopio, se agudiza la pregunta de cómo las estrategias y los lugares de persecución y aniquilación de los reales y "adultos" régimenes autoritarios pudieron pasar "desapercibidos". También en Los rubios el resultado de la reproducción en miniatura es que destaque aún más el "gran panorama" de la historia.

El arte de la memoria se ha basado desde siempre en medidas mnemotécnicas que implican artificios y trucos. De tal manera, no es de sorprender que en las manifestaciones estéticas que recuerdan los crímenes cometidos por el terrorismo de estado se recurra también a ello. En su foto-ensayo Buena Memoria el fotógrafo argentino Marcelo Brodsky inserta una serie de fotografías, shoots de una grabación fílmica, que muestran dos chicos "jugando a morir" (Brodsky 1997: 78-79) ${ }^{30}$-de los cuales uno más tarde será desaparecido-. Brodsky, nacido en 1954, pertenece a otra generación que Carri, pero pareciera precederla en su juego con la memoria de la desaparición. También en la llamada poesía de los noventa, de cuya producción participa la generación HIJOS, el explícito juego mnemotécnico es frecuente. En el poema "Volviendo a la fábrica de nuestros juguetes", de Cristian de Nápoli, dice: "Tomá este ladrillo, saquémoslo del contexto/de un helicóptero de guerra. [...]/ Yo empezaría mi biografía con eso,/ siempre es bueno arrancar por materiales desclasificados [...] " (Nápoli 2007: 13-14). Y Roberta Iannamico, nacida como de Nápoli en 1972, en un ciclo titulado "Mamushkas" habla de unas madres postorgánicas y a la vez totales -"Una mamushka contiene en su vientre la

30 Cf. también la página web mencionada en la bibliografía. Ésta contiene un dispositivo que amalgama los stills del libro en una animación y reproduce el original fílmico. 
totalidad de las Mamushkas" (Iannamico 2002: 1)- ${ }^{31}$ para exhibirlas en su "desnudez" que, como "la cebolla" (Iannamico 2002: 9), invitará a llorar. Resulta difícil leer el texto sin pensar en las madres de Plaza de Mayo. La poesía de Iannamico, como la de Washinton Cucurto, Marina Mariasch o Cecilia Pavón, cultiva un tono infantil; pero justamente esta presunta inocencia encubre lo tenebroso, o se transmuta en ello. Igualmente Mariana Enríquez o Félix Bruzzone declinan en su prosa variantes de la desaparición dentro de una gramática grotesca y pop-gótica. Para concluir: el principio de la caja de construcciones, convertida en caja de de y reconstrucciones, une todas estas aproximaciones al horror histórico. La memoria se entiende en este sentido como proceso abierto que incluye puntos de rotura incontrolables. Abjurando o extraviando los paradigmas de las narraciones completas, eficaces y fidedignas, para seguir más bien la senda del trauma con sus dislocaciones y disociaciones, la memoria de Los rubios puede ser denominada recicladora, un crisol que admite que en el intento de subvertir los mecanismos del olvido entren intereses de interpretación y apropiación dictados por el presente, y también inversiones relativas al futuro. La des/memoria concierne a la destructibilidad, la perdurabilidad y la renovación. No es de sorprender que esto desemboque en la materialidad de las culturas, incluida la industrial; y menos es de sorprender que la propuesta de Albertina Carri, como la de otros integrantes de su generación, caiga en la cuenta de que la memoria es, por ende, un ejercicio y una materia comerciable. Carri misma subraya que su film "no tiene que ver con la memoria de supermercado" (Carri en Moreno 2003). Cabe aquí centrar la atención final de este artículo en la categoría de lo serial. Tanto como la aniquilación de personas por un estado autoritario es resultado de una calculación ideológica y económica, recurre a la vez a un método serial, fundado en la reproducción retórica de estereotipos declarables como "enemigos internos". En el caso argentino "se fabricó la marca subversivo". Los rubios responde al consiguiente y masivo "asesinato en serie" con las figuras seriadas de Playmobil, de las cuales algunas caen. ¿Qué tiene que ver el supermercado con esto? Carri no aclara lo que entiende bajo

31 Por falta de acceso a la publicación de ediciones Vox, de 2002, la referencia corresponde a un manuscrito de la autora. Véase también, junto a una traducción al alemán, en <www.satt.org/latin-log/66.html $>$. 
supermercado; se podrá suponer que alude a lo prefabricado, a la gramática de los surtidos, a la mega-mercantilidad. Pero el supermercado también se basa en el selfservice y justamente en la variedad de ofertas. Conjeturando una memoria puesta en venta, Carri desea una memoria incómoda, que muestre su organismo interno y no solamente su etiqueta. Esta concepción es transferible a otro tópico de su film: "Hay en Los rubios una especie de violencia teñida de melancolía contra la plenitud insospechada de una institución, la familia [...]" (Amado 2003). Albertina Carri no encuentra concordancia con los sistemas establecidos y reiterados; ni admite que sus hermanas sean un referente asegurador. Mientras que de Nápoli pregunta: "Fabián, no te vayas./ ¿Hiciste una casa?/" (Nápoli 2007: 14), parece proponer nuevas selecciones afectivas para habitar la vida. Si las familias son formaciones bio-históricas que lanzan series -mamushkas orgánicas y otras piezas- y que en un colectivo desembocan en lo que son los representantes de un tiempo, a los cuales le sucederán otros, y así sucesivamente, Los rubios como publicación bio-histórica altera las viejas series y crea un reality show que no tiene mucho que ver con los esquemas burgueses. Encadena a quienes integran el film, pero solo mediante un uniforme postizo: las pelucas.

\section{Bibliografía}

Arias, Lola (2009): Mi vida después. Estreno el 27 de marzo en Buenos Aires: Teatro Sarmiento.

Adorno, Theodor W. ([1970] 2002): Ästhetische Theorie. Frankfurt am Main: Suhrkamp.

Agamben, Giorgio (1979): Infanzia e storia. Distruzione dell'esperienza e origine della storia. Torino: Einaudi.

Agamben, Giorgio (2005): Profanazioni. Roma: Nottetempo.

Amado, Ana (2003): "Los infantes del terror. Nota sobre Los rubios, de Albertina Carri”. En: El ojo que piensa. Revista Virtual de Cine Iberoamericano, 3, agosto (<www.elojoquepiensa.udg.mx/espanol/revis_04/secciones/cinejour/artic_04. pdf $>$; 11.11.2008).

- (2009): La imagen justa. Cine argentino y politica 1980-2007. Buenos Aires: Colihue.

anónimo (2005): "Los chicos crecen. El cine sobre la dictadura". En: Página/12 online, 11 de septiembre (<www.pagina12.com.ar/diario/suplementos/radar/9-24982005-09-12.html>; 27.07.2009). 
- (2008/2009): "Biopolítica. Viaje por los desafíos que nos plantean HIJOS". En: Mu, El Periódico de lavaca. Edición temática: Que los parió. Cómo nos está marcando la generación HIJOS, 2, 21, pp. 2-4.

Bachmann, Felicitas (2004): 30 Jahre Playmobil. Königswinter: Heel.

Barthes, Roland (1980): La chambre claire: note sur la photographie. Paris: Gallimard.

Brodsky, Marcelo (1997): Buena Memoria - Good Memory. Buenos Aires: La Marca (<www.zonezero.com/exposiciones/fotografos/brodsky/default.html>; 27.07. 2009).

Cancela, Lorena (2005): "Formas de decir 'yo'. Los rubios, de Albertina Carri". En: Otro campo. Críticas. 16 de agosto (<www.otrocampo.com/festivales/ bsas2003/losrubios.html>; 11.11.2008 y <www.editorial-quipu.galeon.com/ losrubios.htm>; 27.07. 2009).

Canetti, Elias ([1960] 2001): Masse und Macht. Frankfurt am Main: Fischer.

Feinstein, Stephen C. (2000): “Zbigniew Libera's Lego Concentration Camp: Iconoclasm in Conceptual Art About the Shoah". En: Other Voices. The (e)Journal of Cultural Criticism, 2, 1, febrero (<www.othervoices.org/2.1/feinstein/ auschwitz.html>; 11.11.2008).

García, Fernando (2005) "Ezeiza, de la masacre al museo. Entrevista con Fabián Marcaccio". En: Clarín online, 30 de octubre (<www.clarin.com/diario/ 2005/10/30/sociedad/s-04901.htm>; 11.11.2008).

Garibotto, Verónica/Gómez, Antonio (2006): "Más allá del 'formato memoria': la repostulación del imaginario postdictatorial en Los rubios de Albertina Carri". En: A Contra corriente. Una revista de historia social y literatura de América LatinalA Journal on Social History an Literature in Latin America, 3, 2, invierno, pp. 197-126 (<www.ncsu.edu/project/acontracorriente/winter_06/GaribottoGomez.pdf $>$; 11.11.2008).

Hagopian, Kevin Jack (s.d.): "Sin título [Reseña de Los rubios]". En la página del New York State Writers Institute, State University of New York $(<\mathrm{www}$. albany.edu/writers-inst/webpages4/filmnotes/fnf06n3.html>; 27.07.2009).

Hennel, Axel (ed.) (2009): Playmobil Collector 1974-2009. Dreieich: Fantasia.

Holert, Tom (2001): "Mikro-Ökonomie der Geschichte. Das Unausstellbare en miniature". En: Texte zur Kunst, 41, marzo, pp. 57-68 (<www.textezurkunst.de/41/ mikro-oekonomie-der-geschichte/>; 27.07.2009).

Iannamico, Roberta (2002): Mamushkas. Bahía Blanca: Ediciones Vox. También en: Bolte, Rike/Berger, Timo: Latin.Log. Die wöchentliche Gedichtanthologie aus Lateinamerika (<www.satt.org/latin-log/66.html>; 27.07.2009).

Jelin, Elizabeth (2002): Los trabajos de la memoria. Madrid: Siglo XXI.

Kohan, Martín (2004): "La apariencia celebrada". En: Punto de vista, 78, pp. 24-30.

Kristeva, Julia (1980): Pouvoirs de l'horreur. Essai sur l'abjection. Paris: Seuil.

Link, Daniel (2008/2009): "Después de la dictadura. Una hipótesis". En: Mu. El Periódico de lavaca. Edición temática: Que los parió. Cómo nos está marcando la generación HIJOS, verano: p. 10. Además cf. la conferencia en el Simposio "Escribir después de la dictadura", el 14 de noviembre de 2008 en Berlín. 
Macón, Cecilia (2004): "Los rubios o del trauma como presencia". En: Punto de vista, 80, pp. 44-47.

Meueler, Christof (2009): "Das Fahrzeug wechseln. Niedlichkeit und Sozialismus. Anmerkungen zu Playmobil". En: Junge Welt online. Sumplemento "Kinder", 30 de mayo (<www.jungewelt.de/beilage/art/2035>; 27.07.2009).

Molinero, Cecilia (2003): "Los rubios, una bocanada de aire fresco". En: Revista Solocortos, mayo (<www.solocortos.com/RevistaSC.aspx?nroArticulo=58>; (27.07.2009).

Moreno, María (2003): "Esa rubia debilidad". En: Página/12. Radar online. 19 de octubre (<www.pagina12.com.ar/diario/suplementos/radar/9-1001-2003-1022.html >; 27.07.2009).

Moreno, María (2008/2009): "La pregunta incómoda. Pasajes de una conversación con Daniel Feierstein...”. En: Mu. Edición temática: Que los parió. Cómo nos está marcando la generación HIJOS, 2, 21, p. 5.

Muir, Kate (2008): “The Dark Ages. Reinventing Playmobil for Modern Times". En: Times online, 3 de mayo (<www.women.timesonline.co.uk/tol/life_and_style/ women/the_way_we_live/article3831553.ece>; 27.07.2008).

Nápoli, Cristian de (2007): Los animales. Buenos Aires: Bajo la luna.

Nouzeilles, Gabriela (2005): "Postmemory Cinema and the Future of the Past in Albertina Carri's Los Rubios”. En: Journal of Latin American Cultural Studies, 14, 3, diciembre, pp. 263-278.

Sábato, Ernesto ([1984] 2001): "Prólogo". En: Nunca Más. Informe de la Comisión Nacional sobre la Desaparición de Personas (CONADEP). Buenos Aires: Eudeba, pp. 7-11.

Scott, Anthony O. (2004): "Personally Political: Fallout From the 'Dirty War"'. En: The New York Times online, 7 de abril. (<www.nytimes.com/2004/04/07/movies/ film-review-personally-political-fallout-from-the-dirty-war.html >; 11.11.2009).

Sontag, Susan (1977): On photography. New York: Farrar, Straus and Giroux.

- (2003): Regarding the Pain of Others. New York: Farrar, Straus and Giroux.

Sosa, Cecilia (2003): "Ojos bien abiertos. Una recorrida por las películas en que las nuevas generaciones se asoman al trauma de la dictadura militar". En: Pagina/12 digital, 19 de octubre (<www.pagina12.com.ar/diario/suplementos/radar/ subnotas/1001-179-2003-10-22.html>; 27.07.2009).

WHO (World Health Organization) (2009): International Classification of Diseases (ICD) (<www.who.int/classifications/icd/en/>; 27.07.2009).

WIN (2004): "Playmobil. Made in Germany". En: Welt online, 12 de noviembre (<www.welt.de/print-wams/article115407/Playmobil.html>; 27.07.2009).

\section{Filmografía}

Agresti, Alejandro (1996): Buenos Aires viceversa. $122 \mathrm{~min}$. Argentina/Holanda. Ávila, Benjamín (2004): Nietos (Identidad y Memoria). 75 min. Argentina.

Benigni, Roberto (1997): La vita è bella. $116 \mathrm{~min}$. Italia.

Birabén, Gastón (2003): Cautiva. 113 min. Argentina. 
Bechis, Marco (1999): Garage Olimpo. 98 min. Argentina/Italia/Francia.

- (2002): Figli/Hijos. 92 min. Argentina/Italia.

Caetano, Adrián (2006): Buenos Aires 1977/Crónica de una fuga. Basado en la novela Pase libre - La fuga de la Mansión Sere de Claudio Tamburrini. 105 min. Argentina.

Céspedes, Marcelo/Guarini, Carmen (2002): H.I.J.O.S., el alma en dos. 80 min. Argentina.

Carri, Albertina (2003): Los rubios. Guión en colaboración con Alan Pauls. 89 min. Argentina/Estados Unidos. Trailer en YouTube (2007): <www.youtube.com/ watch? $\mathrm{v}=\mathrm{oKmWK}$ frgzWgmin.1,54> (27.07.2009). Tomas finales en Youtube (2009): <www.youtube.com/watch?v=bxwgCfqMQXImin.7,14>; (27.07.2009) $\left(<\right.$ www.youtube.com $/$ watch? $\mathrm{v}=4 \mathrm{oW} \_Y W O S q K Q \&$ feature $=$ related $>$; 22.02.2010).

Ludin, Norbert/Milstein, Pablo (2002): Sol de noche. Con textos de Marcelo Birmajer. $72 \mathrm{~min}$. Argentina.

Meerapfel, Jeanine (1989): La amiga. En colaboración con Osvaldo Bayer y Agnieszka Holland. 108 min. Argentina.

Olivera, Héctor (1986): La noche de los lápices. Según un libro de María Seoane y Héctor Ruiz Núñez. 105 min. Argentina.

Pelzmajer, Paola (2006): Me moria. 1,01 min. En: YouTube (2008): $<$ www.youtube.com/watch?v=OiUIAvuGLEA\&feature=related $>(29.07 .2009)$.

Pereira, Miguel (1988): Verónico Cruz: La deuda interna. 98 min. Argentina/Gran Bretaña.

Pérez, Miguel (1986): La república perdida II. Con textos de María Elena Walsh. 140 min. Argentina.

Piñeyro, Marcelo (2002): Kamchatka. 103 min. Argentina/España.

Puenzo, Luis (1985): La historia oficial. 110 min. Argentina.

Rodríguez, Manane (2001): Los pasos perdidos. 93 min. Argentina/España.

Solanas, Fernando (1987): Sur/Le Sud. 129 min. Argentina/Francia.

Solomonoff, Julia (2004): Hermanas. $88 \mathrm{~min}$. Argentina/Brasil/España.

Toro, Guillermo del (2006): El laberinto del fauno. 112 min. España/México.

Torre, Pablo (1998): La cara del ángel. 92 min. Argentina.

\section{Enlaces}

EEAF (Equipo de Antropología Forense Argentina): <www.eaaf.org/> (29.07.2009).

Ex-centro clandestino de detención "Club Atlético": <www.ensantelmo.com/ Historia/Historia/En\%20este\%20lugar/antorch_despa_comp.htm> (29.07.2009).

Ex-centro clandestino de detención "El Sheraton": <www.nuncamas.org/ccd/s/ sheraton.htm> (29.07.2009).

CCD (Lista de ex-Centros Clandestinos de Detención): <www.nuncamas.org/ccd/ ccdlist.htm> (29.07.2009).

Cooperativa Lavaca: <www.lavaca.org/> (29.07.2009). 
Parque de la Memoria Buenos Aires: <www.parquedelamemoria.org.ar/home/ select.htm> (29.07.2009).

Playmobil: <www.playmobil.de> (29.07.2009).

Playmobil Fan-Site: <www.gardenwargaming.com/> (29.07.2009).

War-Gaming: <www.brickspire.com/2009/05/16/wargaming-with-toys/> (29.07.2009).

Wikipedia/Películas sobre dictadura militares en Latinoamérica: <www. en.wikipedia.org/wiki/Films_depicting_Latin_American_military_dictatorships> (29.07.2009).

\section{Música}

García, Charly (2002): Influencia. 41 min. Charly García/Emi Music. 